Research Article

\title{
Forming Mechanism of High-Speed Cold Roll Beating of Spline Tooth
}

\author{
Ting Niu, ${ }^{1,2}$ Yong-Tang Li $\mathbb{D}^{1,2}$ Zhi-Qi Liu $\mathbb{D}^{2,3}$ and Hui-Ping Qi ${ }^{1,2}$ \\ ${ }^{1}$ School of Materials Science and Engineering, Taiyuan University of Science and Technology, Taiyuan 030024, China \\ ${ }^{2}$ Shanxi Key Laboratory of Metallic Forming Theory and Technology, Taiyuan 030024, China \\ ${ }^{3}$ School of Mechanical Engineering, Taiyuan University of Science and Technology, Taiyuan 030024, China
}

Correspondence should be addressed to Zhi-Qi Liu; 273038389@qq.com

Received 29 January 2018; Accepted 20 March 2018; Published 15 April 2018

Academic Editor: Guru P. Dinda

Copyright $\odot 2018$ Ting Niu et al. This is an open access article distributed under the Creative Commons Attribution License, which permits unrestricted use, distribution, and reproduction in any medium, provided the original work is properly cited.

\begin{abstract}
The spline tooth of ASTM 1045 was fabricated by high-speed cold roll-beating (HSCRB) process at room temperature. Microhardness of the spline tooth was examined by a nanoindenter. The grains and misorientation angle distributions were measured by electron backscatter diffraction (EBSD). The results showed that the microhardness was improved up to $1280 \mu \mathrm{m}$ deep from the surface of the spine tooth. The microhardness and the grain sizes gradually decreased in the direction away from the surface. On the surface, the fraction of ultrafine grains increased up to about $90 \%$, and the average grain diameter (which was $\sim 0.56 \mu \mathrm{m}$ ) decreased by $71.4 \%$. The model of grain evolution during HSCRB process is proposed in this work. New grains appear first on the boundaries of the elongated grains within numerous subgrains. The elongated grains are refined as a result of subgrain rotation. By analyzing the HSCRB technical principle, we concluded that the process parameters affect the refinement degree of studied steel by determining beating pass, beating pass interval time, and strain rate.
\end{abstract}

\section{Introduction}

With the development of important industries, such as aircrafts, wind turbines, and nuclear power, a spline formed by current cutting methods fails to meet their high requirements. The spline formed by high-speed cold roll-beating (HSCRB) process possesses many advantages, such as higher strength and hardness and wear resistance. Moreover, the HSCRB is an advanced manufacturing technology with high efficiency and energy saving relative to the cutting formation and has been widely used in the above fields [1-3]. However, in our opinion, HSCRB process has not been studied in detail. Over past decades, many studies were dedicated to material flow, dislocation density, residual stress, and cold working hardening during HSCRB process. Cui et al. analyzed the trend of material flow based on the principle of constant volume and minimum moving resistance [4]. Lei studied the flow path trends of the special nodes by using the finite element simulation [5]. Wang et al. obtained dislocation density curve of $40 \mathrm{Cr}$ under various strain rates [6].
The effects of process parameters on the distribution of residual stress and cold working hardening were discussed by Feng and Xie [7, 8]. However, we could not find reports associated with the evolution of the microstructure during HSCRB process.

The development of ultrafine grained materials using severe plastic deformation (SPD) has attracted considerable attention. Many SPD techniques could be used to fabricate materials with ultrafine grains, for example, equal-channel angular pressing (ECAP) [9, 10], high-pressure torsion (HPT) $[11,12]$, accumulative roll bonding (ARB) [13], and differential speed rolling (DSR) [14, 15].

Ryttberg et al. [16] observed the microstructure evolution of cold rolling with ratios ranging from 1.05 to 1.5 using electron backscatter diffraction (EBSD). He demonstrated that the deformation degree decreased in the direction from the inner diameter towards the outer diameter of the rings. The deformation took place in the ferrite matrix while the carbides appeared unaffected. Park et al. [17] and Lee et al. [18] found that the ultrafine grains were more pronounced 


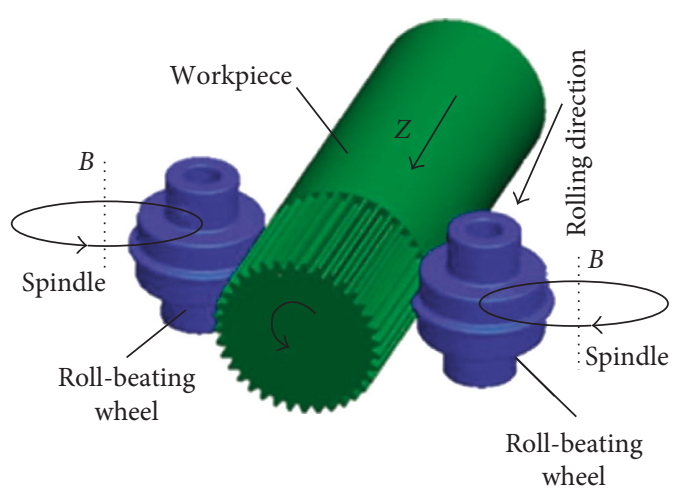

Figure 1: Schematic diagram of the HSCRB principle.

in the top of the ring formed by cold ring rolling. The deformation-induced grain subdivision with high-angle boundaries (HABs) was the primary mechanism in grain refinement. The HABs formed via the subdivision process could be the result of the subgrain rotation. Hamad reported the microhardness, microstructure, and texture evolution of interstitial free steel during differential speed rolling (DSR) processing. The results showed that the grain refinement was caused by dynamic recrystallization, and new grains formed along the original grain boundaries, leading to a uniform distribution of near-equiaxed ultrafine grains with the increase of the introduced deformation level [19]. The sheets of 0.18 wt.\% carbon steel with the ultrafine microstructure produced by DSR were obtained. The result of the microstructure and texture during DSR revealed the mechanism of ferrite refinement of IF steel [20]. Sakai et al. discussed several mechanisms of strain-induced ultrafine grain (UFG) formation during SPD and developed the schematic models of UFG under SPD. The continuous increase in misorientation between subgrains during SPD was an essential feature of the strain-induced formation of UFGs [21].

Thus, EBSD is an effective method to clarify the deformation mechanism of SPD. The abovementioned conclusions on the evolution of the microstructure during DSR and usefulness of EBSD led us to establish the goal of the study: in this work, we attempted to reveal the strengthening mechanism of the spline tooth formed by HSCRB with EBSD.

\section{Experiment}

Quenched and tempered ASTM 1045 steel with $0.430 \%$ C, $0.290 \% \mathrm{Si}, 0.630 \% \mathrm{Mn}, 0.019 \% \mathrm{P}$, and $0.014 \% \mathrm{~S}$ was used as a starting material. The schematic diagram of the HSCRB principle is presented in Figure 1. Two roll-beating wheels are installed on the rolling spindles. The two roll-beating wheels driven by the rolling spindle rotate at same speed in the opposite direction. The speed of the roll-beating wheels is $1400 \mathrm{r} / \mathrm{min}$. The workpiece feeds continuously along the $Z$ axis and rotates discontinuously. The workpiece feed speed is $1.5 \mathrm{~mm} / \mathrm{s}$. At room temperature, the workpiece is beaten once every time the roll-beating wheel rotates one circle. When the workpiece is not beaten, it rotates at a relative angle of one tooth. The spline tooth is formed on the entire

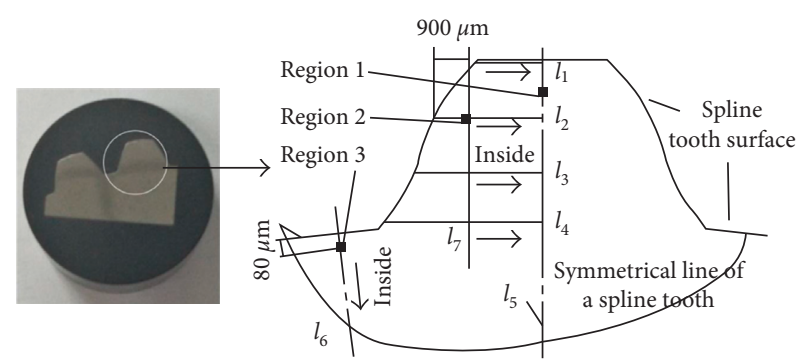

FIgURE 2: Schematic illustration of the test regions.

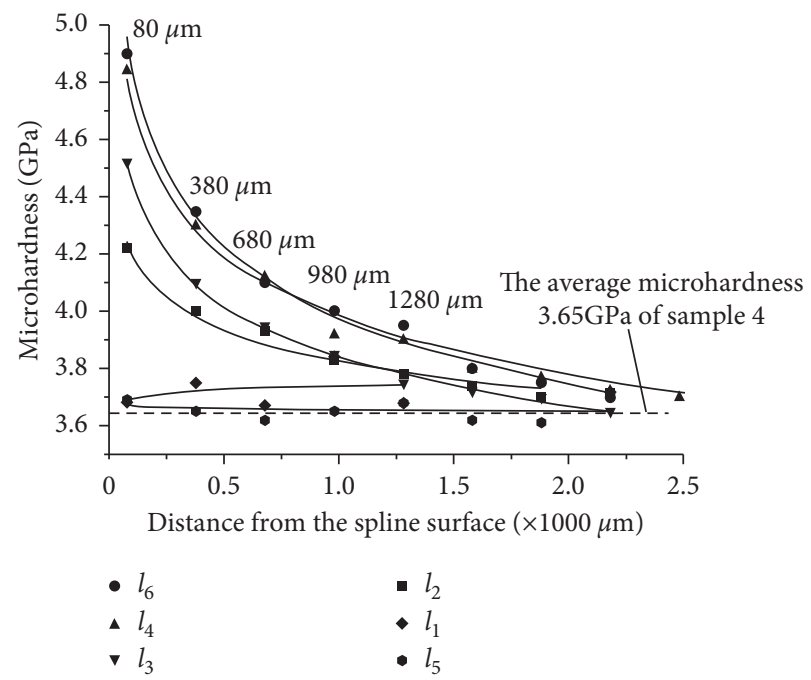

FIGURE 3: Microhardness of the spline tooth surface as the function of depth.

surface of the workpiece along the $Z$ axis as a result of accumulation [1].

As shown in Figure 2, the microhardness along $l_{1}, l_{2}, l_{3}, l_{4}$, $l_{5}$, and $l_{6}$ was detected using nanoindenter Agilent G200. The sample preparation for the EBSD examinations consisted of argon ion polishing and cutting the sheet in the normal direction-rolling direction (ND-RD). The cutting lines of the sample 1,2 , and 3 were $l_{5}, l_{7}$, and $l_{6}$, respectively. The test region 1 on the sample 1 was located on the symmetry line of a spline tooth. The test region 2 on the sample 2 and test region 3 on the sample 3 were about $900 \mu \mathrm{m}$ and $80 \mu \mathrm{m}$ away from the spline tooth surface, respectively. The sample 4 was prepared by cutting the initial sample. The misorientation angle and microstructure of the samples were observed by EBSD with a field-emission scanning electron microscope of $20 \mathrm{kV}$; the data were analyzed using a HITACHI S-3400N analyzer. In this study, the misorientation angles from $2^{\circ}$ to $10^{\circ}$ indicated the low-angle boundaries (LABs), and the misorientation angles higher than $10^{\circ}$ indicated the highangle boundaries (HABs).

\section{Results}

3.1. Microhardness. Due to the surface roughness, the test region could not be located on the spline tooth surface. Thus, the microhardness of the region located $80 \mu \mathrm{m}$ deep was almost 


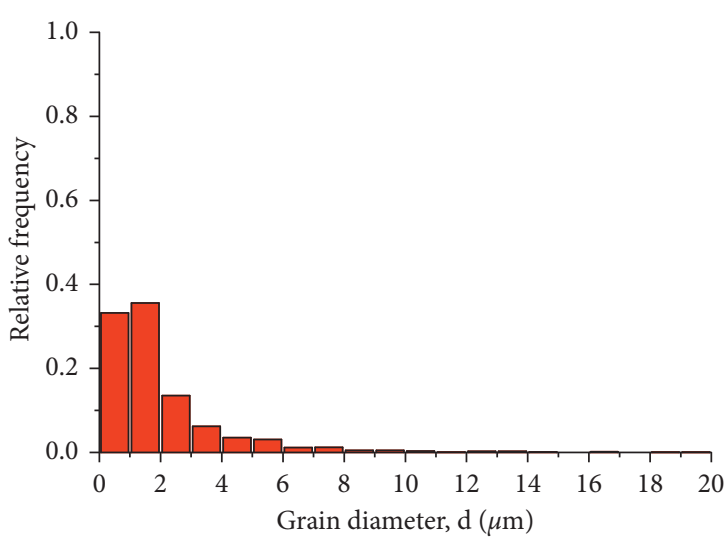

(a)

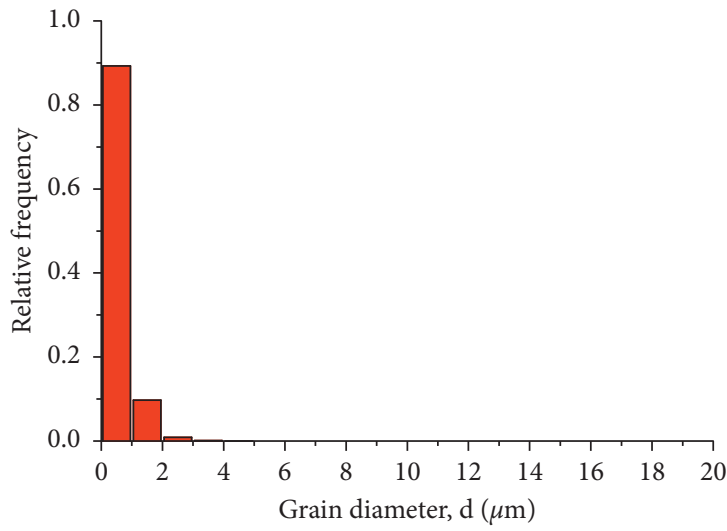

(c)

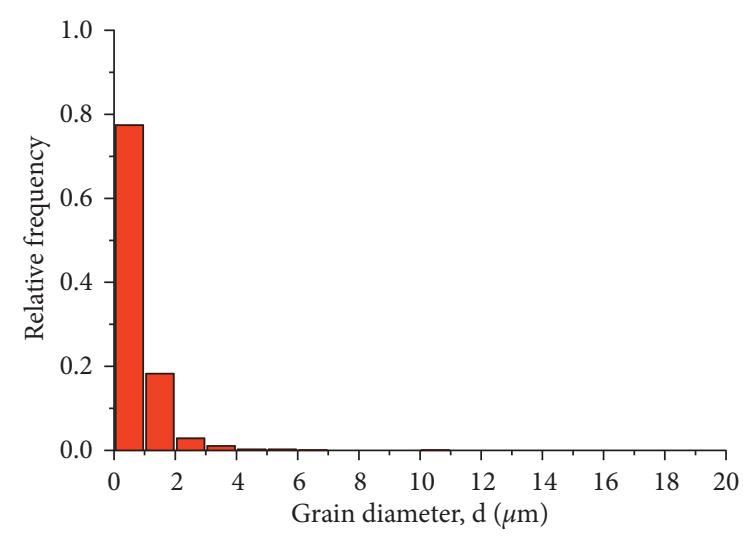

(b)

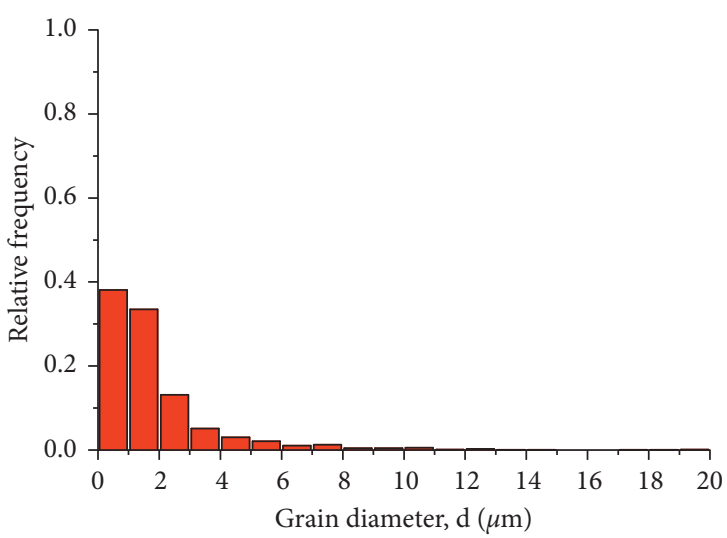

(d)

FIGURE 4: Grain diameter distribution in (a) region 1 of sample 1, (b) region 2 of sample 2, (c) region 3 of sample 3, and (d) sample 4.

the same as the microhardness on the spline surface. Figure 3 shows that from the spline tooth surface to $1280 \mu \mathrm{m}$ region, the microhardness gradually decreased to the microhardness of sample 4 with the average value of $3.65 \mathrm{GPa}$. Microhardness values along $l_{1}$ and $l_{5}$ are exception to this observation: $l_{1}$ is located on the boundary, and the microhardness along $l_{1}$ was unstable. The microhardness along $l_{5}$ was roughly equal to the microhardness of sample 4 .

3.2. Grain Distribution. Typically, the grains with size ranging from 0.1 to $1 \mu \mathrm{m}$ are called "ultrafine grains" and in the range of $1-10 \mu \mathrm{m}$ are called "fine grains." Figure 4 shows that the average grain diameter was $2.09 \mu \mathrm{m}$ in region 1 , and the average grain diameter was $2.03 \mu \mathrm{m}$ in sample 4 . Thus, the average grain diameter in region 1 was roughly equal to the average grain diameter of the initial sample. In both regions, the ultrafine grains corresponded to approximately 35\%. In region 2 , the average grain diameter was $0.75 \mu \mathrm{m}$, and the fraction of ultrafine grains was $>77 \%$. The average grain diameter decreased by $63.1 \%$ comparing to the initial sample. In region 3, the average grain diameter was $0.56 \mu \mathrm{m}$, and the fraction of ultrafine grains reached up to $90 \%$ and $100 \%$ in fraction of all the fine grains. The average grain diameter decreased by approximately $71.4 \%$ comparing to the initial sample.

\section{Discussion}

The microhardness in region 1 located in the symmetrical line of a spline tooth was roughly equal to that of the initial sample. The average grain diameter of $2.09 \mu \mathrm{m}$ in region 1 was equal to the average grain diameter of the initial sample $(2.03 \mu \mathrm{m})$. Ultrafine grains contributed approximately $35 \%$ in the both regions. Therefore, in both regions, the microhardness was almost equal and grain refinement degrees were almost the same.

In regions 2 and 3 , the microhardness increased significantly relative to the values of the initial sample within $1280 \mu \mathrm{m}$ deep from the spline surface, and the microhardness in region 2 was higher than that in region 3 . In region 2, the average grain diameter was $0.75 \mu \mathrm{m}$, which decreased by $63.1 \%$ relative to the initial grain diameters. In region 3 , the average grain diameter was $0.56 \mu \mathrm{m}$, which decreased by $71.4 \%$ relative to the initial grain diameters. The fraction of the ultrafine grains in the region 2 was over $77 \%$ and reached $90 \%$ in region 3 . Therefore, in regions 2 and 3, the average grain diameters decreased significantly, and the fraction of the ultrafine grains increased significantly as well relative to the initial sample. Grain refinement degree in region 2 was higher than that in region 3 .

The microhardness of the high cold roll-beating spline is closely related to the grain refinement degree during HSCRB. 


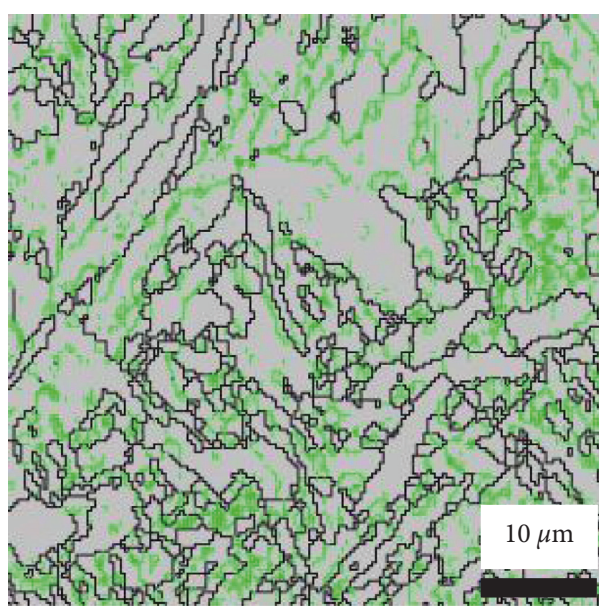

(a)

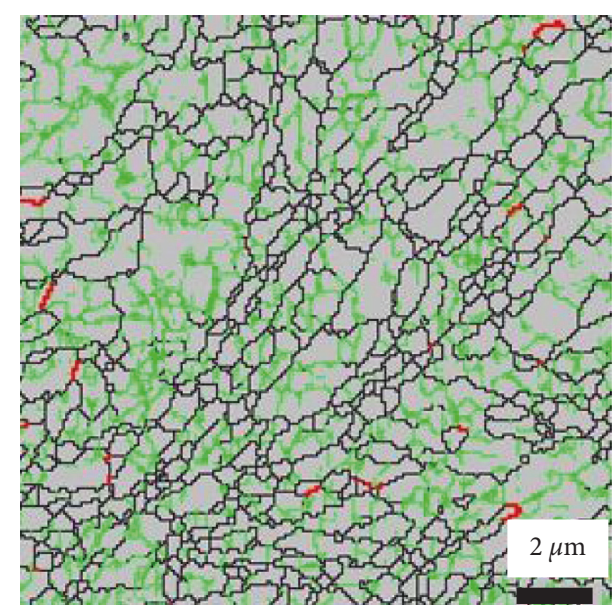

(b)

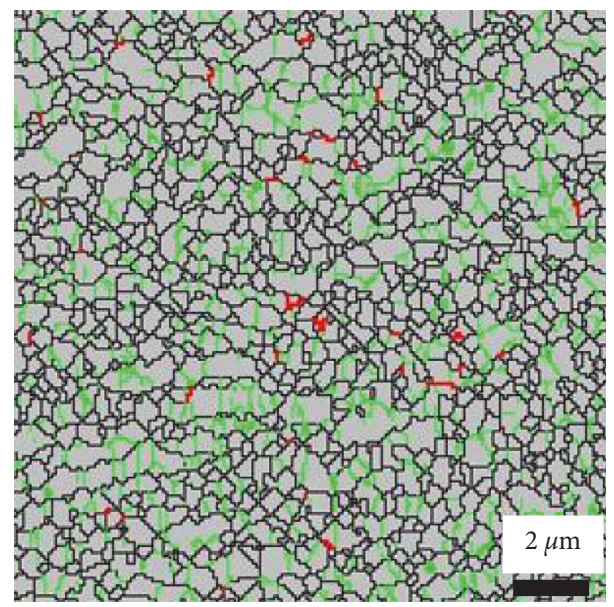

(c)

Figure 5: (a) Grain boundaries maps in (a) sample 4, (b) region 2 of sample 2, and (c) region 3 of sample 3.

The greater the degree of grain refinement, the higher the microhardness is. Grain refinement is one of the main reasons for the property improvement of spline tooth obtained using the HSCRB process.

4.1. Grain Refinement Mechanisms. The deformation level is significantly larger at the surface and decreases gradually within the tooth itself deep down from the surface. Therefore, the evolution of ultrafine grains can be confirmed by studying the microstructure changes from the inside to the spline tooth surface. The microstructure of region 1 consisted mainly of large randomly distributed grains (Figure 5(a)). The microstructure of region 2 consisted of the elongated grains within many subgrains, oriented along certain directions, and ultrafine grains along boundaries of the elongated grains (Figure 5(b)). The microstructure of region 3 consisted mostly of ultrafine grains and fine grains with only minor admixtures of the elongated grains (Figure 5(c)). Those microstructures formed because of the grain nucleation by a typical continuous dynamical recrystallization (CDRX) during severe plastic deformation (SPD) [16-18].

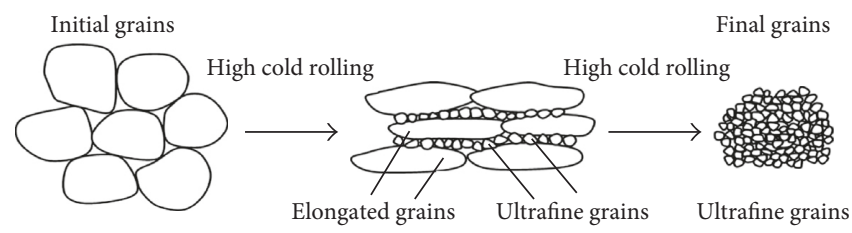

Figure 6: The evolution model of the deformation-induced grain subdivision during HSCRB process.

Figure 6 presents the evolution schematic of the deformationinduced grain subdivision during HSCRB. The grains are elongated first. Concurrently, high dislocation density was produced in the elongated grains, and the number of dislocation cells and dislocation density of the cell wall increased [21]. As a result, the subgrains with LABs appeared. The new grains were formed preferentially along the boundaries of the elongated grains. This is an intermediate stage (shown in Figure 5(b)): a mixture of elongated grains within many subgrains with LABs and the new grains formed along the boundaries of the elongated grains. Therefore, as shown in Figure 7(b), the fraction of LABs $\left(f_{\text {LABs }}\right)$ in region 2 equals to $28.39 \%$ is higher than in regions 


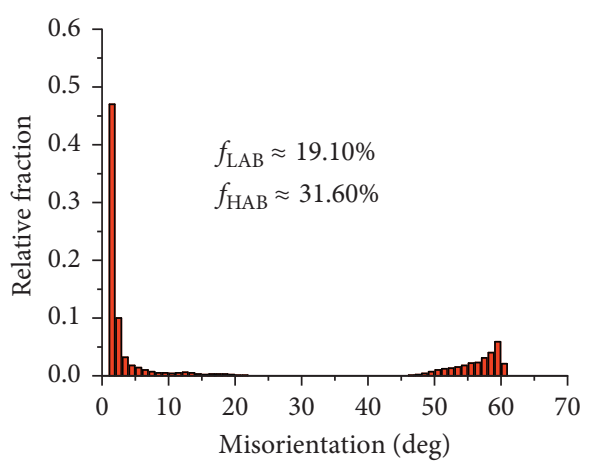

(a)

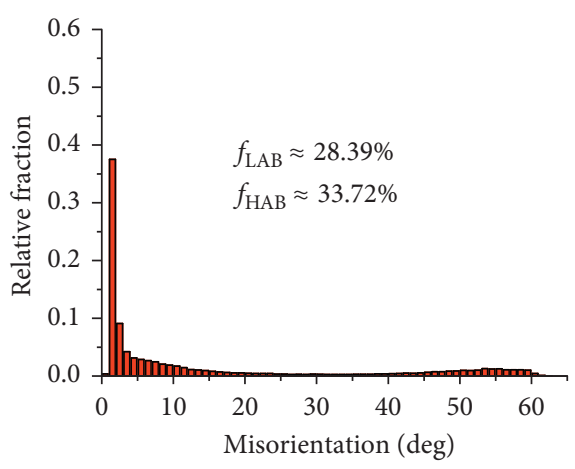

(b)

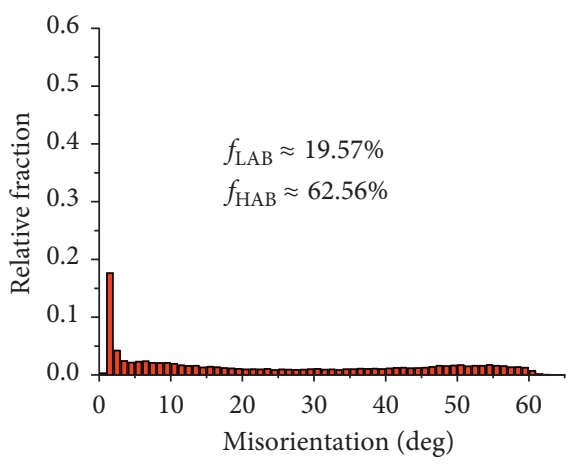

(c)

Figure 7: The fractions of LABs and HABs in (a) sample 4, (b) region 2 of sample 2, and (c) region 3 of sample 3.

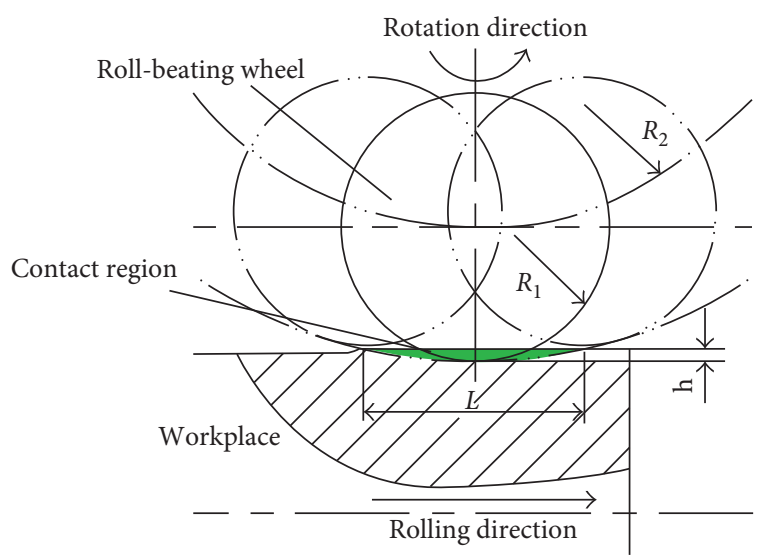

FIGURE 8: Schematic of the contact area, in which a roll-beating wheel beats the workpiece.

1 (Figure $7(\mathrm{a})$ ) and 3 (Figure $7(\mathrm{c})$ ). When closing to the surface, the deformation level was larger and the number of subgrains with the LABs decreased. Concurrently, a lot of ultrafine grains with the HABs appeared as a result of subgrain rotation [17]. Therefore, as shown in Figure 7(c), the fraction of HABs $\left(f_{\mathrm{HABs}}\right)$ in region 3 equals to $62.56 \%$ is the highest.

4.2. Analysis of the Process Parameters. According to the results, the grain refinement extent at the spline tooth surface is the highest. With the high-speed rotation of the roller and the microfeed of the workpiece, the spline tooth surface is roll beaten quickly and repeatedly over multipasses by the roll-beating wheel during HSCRB. The rotation speed of the roller and the feed speed of the workpiece are two important process parameters, which affect the deformation level by the beating pass, the beating pass interval time, and the strain rate. The beating pass interval time is determined by the rotation speed of the roller. The strain rate is determined by the rotation speed of the roller, the mass of the roll-beating wheel, and the rotation radius of the roll-beating wheel. It is very important to study how these three parameters affect the deformation and will be researched in our future work.

As presented in Figure 8, the green region is the contact area where a roll-beating wheel beats the workpiece once. The beating pass can be obtained as

$$
N=\frac{n \sqrt{\left(R_{1}+R_{2}\right)^{2}-\left(R_{1}+R_{2}-h\right)^{2}}}{30 z \cdot f},
$$

where $N$ is the beating pass, $n$ is the spindle speed of the roller, $R_{1}$ is the radius of a roll-beating wheel, $R_{2}$ is the rotation radius of roll-beating wheels, $h$ is the height of spline tooth, $f$ is the workpiece feed rate, and $z$ is spline tooth number.

\section{Conclusions}

Samples of medium carbon steel were processed using HSCRB at room temperature to form a spline tooth. The deformation-induced grain refinement mechanism and the 
microhardness of the spline tooth were studied. The following conclusions were reached:

(1) The fraction of ultrafine grains could reach up to about $90 \%$ on the surface of spline tooth formed by HSCRB. The microhardness of the spline tooth decreases gradually deep down from the surface.

(2) Grain refinement is one of the main reasons for the property improvement of the spline tooth obtained using HSCRB process.

(3) During HSCRB process, the new ultrafine grains were nucleated along the boundaries of newly formed elongated grains; subgrains with LABs appeared inside elongated grains. Subsequently, the ultrafine grains with HABs formed in the elongated grains as a result of the rotation of subgrains with the increase of the deformation level.

(4) The beating pass, the beating pass interval time, and the strain rate are the key parameters affecting the grain refinement degree during HSCRB process.

\section{Conflicts of Interest}

The authors declare that they have no conflicts of interest.

\section{Acknowledgments}

The authors would like to acknowledge the financial supports of the National Natural Science Foundation of China (nos. 51475316 and 51275331) and the Shanxi Key Subjects Construction.

\section{References}

[1] T. Niu, Y. T. Li, and Z. Q. Liu, "Motion parameters analysis and kinematics simulation of actuator of spline cold rolling device," Journal of Mechanical Design, vol. 4, pp. 41-45, 2014, in Chinese.

[2] Y. T. Li, L. Ju, and T. Niu, Research Status and Development Trend on Cold Forming of Tooth-Like Shaft Parts, Taiyuan University of Science and Technology, Taiyuan, China, 2015, in Chinese.

[3] F. K. Cui, C. Guo, and Y. X. Li, "Flow stress characteristics and dynamic constitutive model for 40Cr steel," Journal of Henan University of Science and Technology Natural Science, vol. 5, pp. 1-5, 2012, in Chinese.

[4] F. K. Cui, X. Q. Wang, F. Zhang, H. Xu, J. Quan, and Y. Li, "Metal flowing of involute spline cold roll-beating forming," Chinese Journal of Mechanical Engineering, vol. 26, no. 5, pp. 1056-1062, 2013, in Chinese.

[5] S. J. Lei, Theoretical and Simulation Study on Cold Forming of Spline, Taiyuan University of Science and Technology, Shanxi, China, 2010, in Chinese.

[6] X. Q. Wang, F. Cui, G. Yan, and Y. Li, "Study on dislocation change during cold roll-besting of 40Cr," China Mechanical Engineering, vol. 24, no. 16, pp. 2248-2256, 2013, in Chinese.

[7] Z. Feng, Influence of Process Parameters on Residual Stress and Parameter Optimization of High-Speed Cold Rolling, Henan University of Science and Technology, Henan, China, 2014, in Chinese.
[8] Y. F. Xie, Study on Influence Mechanism of Cold-work Hardening of Cold Roll Forging at High Speed on Forming Quality, Henan University of Science and Technology, Henan, China, 2014, in Chinese.

[9] W. Polkowski, P. Jozwik, M. Polanski, and Z. Bojar, "Microstructure and texture evolution of copper processed by differential speed rolling with various speed asymmetry coefficient," Materials Science and Engineering: A, vol. 564, pp. 289-297, 2013, in Chinese.

[10] K. Hamad, B. K. Chung, and Y. G. Ko, "Microstructure and mechanical properties of severely deformed $\mathrm{Mg}-3 \% \mathrm{Al}-1 \% \mathrm{Zn}$ alloy via isothermal differential speed rolling at $453 \mathrm{~K}$," Journal of Alloys and Compounds, vol. 615, pp. s590-s594, 2014.

[11] Loorentz and Y. G. Ko, "Microstructure evolution and mechanical properties of severely deformed al alloy processed by differential speed rolling," Journal of Alloys and Compounds, vol. 536, no. S1, pp. S122-S125, 2012.

[12] W. J. Kim, K. E. Lee, and S. H. Choi, "Mechanical properties and microstructure of ultra fine-grained copper prepared by a high-speed-ratio differential speed rolling," Materials Science and Engineering: A, vol. 506, no. 1-2, pp. 71-79, 2009.

[13] W. J. Kim, S. J. Yoo, and J. B. Lee, "Microstructure and mechanical properties of pure Ti processed by high-ratio differential speed rolling at room temperature," Scripta Materialia, vol. 62, no. 7, pp. 451-454, 2010.

[14] Y. G. Ko, J. Suharto, J. S. Lee, B. H. Park, and D. H. Shin, "Effect of roll speed ratio on deformation characteristics of if steel subjected to differential speed rolling," Metals and Materials International, vol. 19, no. 3, pp. 603-609, 2013.

[15] J. Suharto and Y. G. Ko, "Annealing behavior of severely deformed IF steel via the differential speed rolling method," Materials Science and Engineering: A, vol. 558, pp. 90-94, 2012.

[16] K. Ryttberg, M. Knutson Wedel, V. Recina, P. Dahlman, and L. Nyborg, "The effect of cold ring rolling on the evolution of microstructure and texture in 100Cr6 steel," Materials Science and Engineering: A, vol. 527, no. 9, pp. 2431-2436, 2010.

[17] J. H. Park, K. Hamad, I. P. Widiantara, and Y. G. Ko, "Strain and crystallographic texture evaluation of interstitial free steel cold deformed by differential speed rolling," Materials Letters, vol. 147, pp. 38-41, 2015.

[18] S. H. Lee, Y. Saito, N. Tsuji, H. Utsunomiya, and T. Sakai, "Role of shear strain in ultragrain refinement by accumulative roll-bonding (ARB) process," Scripta Materialia, vol. 46, no. 4, pp. 281-285, 2002.

[19] K. Hamad, B. K. Chung, and Y. G. Ko, "Effect of deformation path on microstructure, microhardness and texture evolution of interstitial free steel fabricated by differential speed rolling," Materials Characterization, vol. 94, pp. 203-214, 2014.

[20] K. Hamad, R. B. Megantoro, and Y. G. Ko, "Microstructure and texture evolution in low carbon steel deformed by differential speed rolling (DSR) method," Journal of Materials Science, vol. 49, no. 19, pp. 6608-6619, 2014.

[21] T. Sakai, A. Belyakow, R. Kaibyshev, H. Miura, and J. J. Jonas, "Dynamic and post-dynamic recrystallization under hot, cold and severe plastic deformation conditions," Progress in $\mathrm{Ma}$ terials Science, vol. 60, pp. 130-207, 2014. 


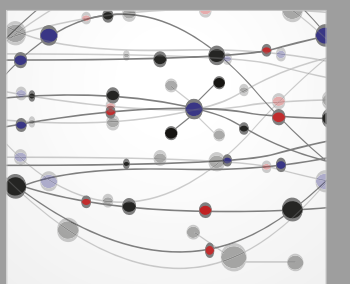

The Scientific World Journal
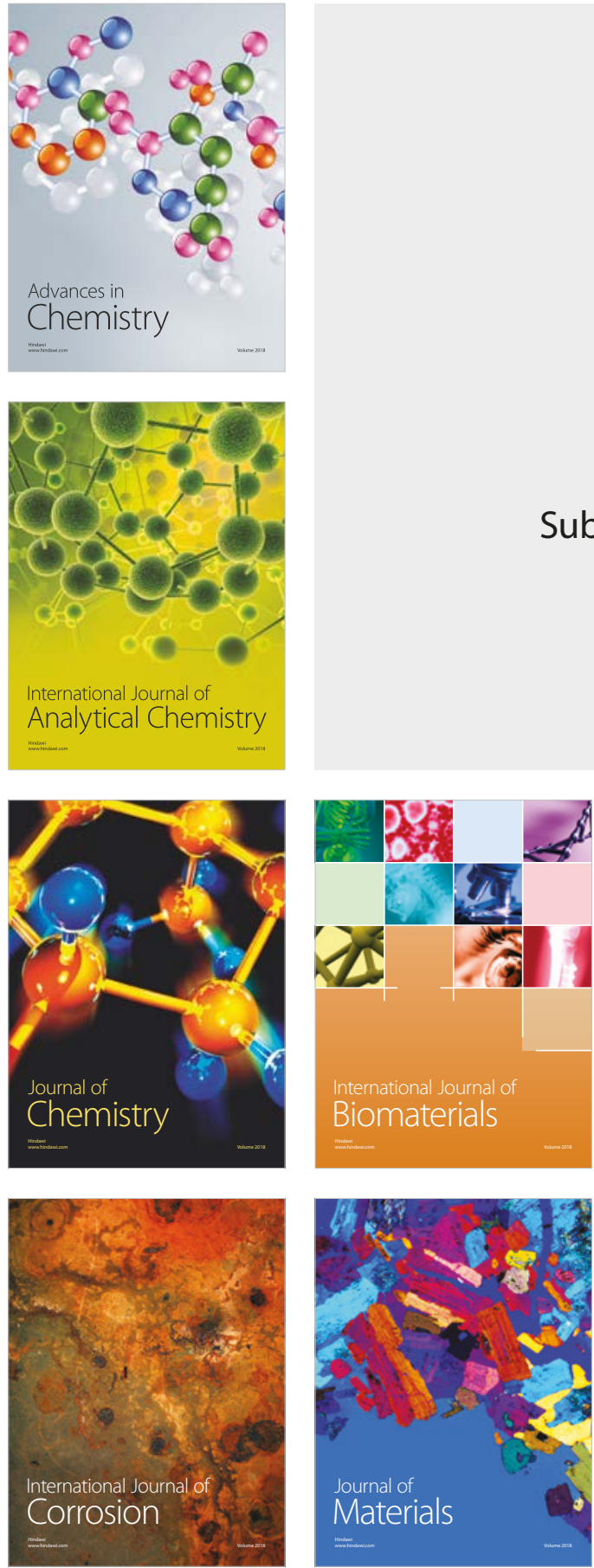

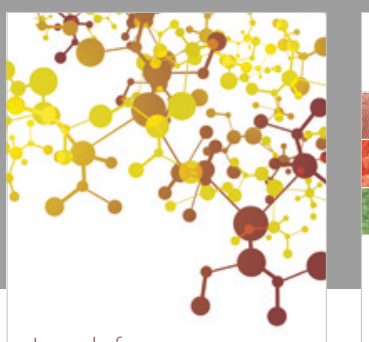

Journal of

Applied Chemistry
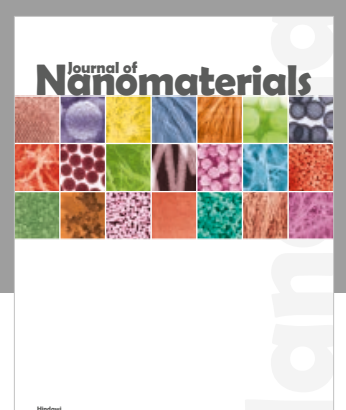

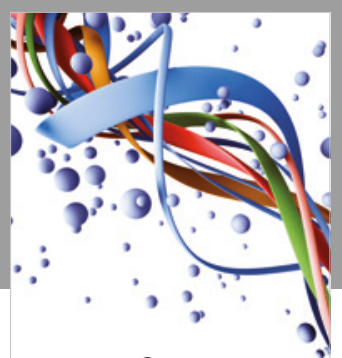

Scientifica

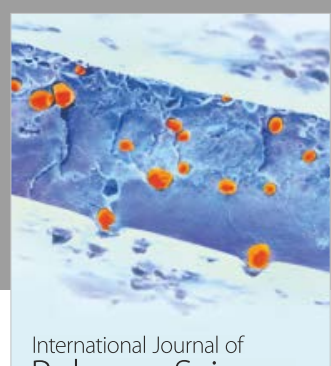

Polymer Science

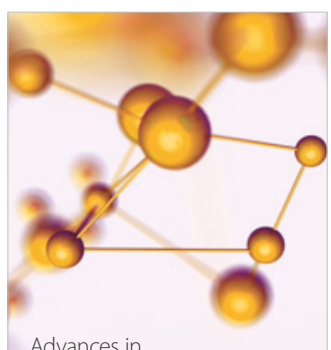

Physical Chemistry
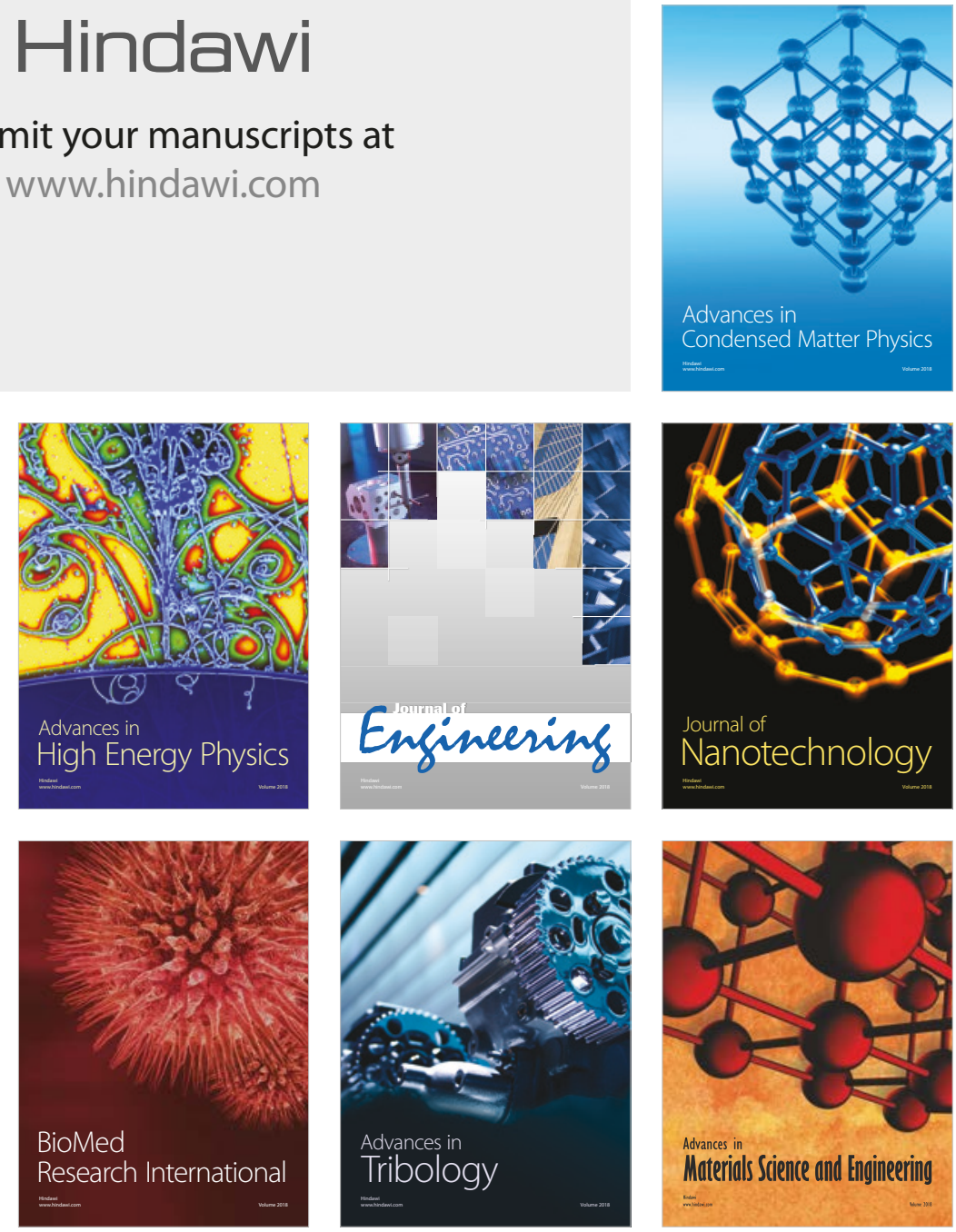